Journal of Engineering and Applied Sciences 15 (7): 1676-1686, 2020

ISSN: 1816-949X

(C) Medwell Journals, 2020

\title{
The Effect of Organizational Learning, Core Organizational Competence and Diversification Strategy on Organizational Performance (Study at Private Universities in NTT Province)
}

\author{
${ }^{1}$ Rafael Octavianus Byre, ${ }^{2}$ Ubud Salim, ${ }^{2}$ Sudjatno and ${ }^{2}$ Kusuma Ratnawati \\ ${ }^{1}$ Department of Management Science, \\ ${ }^{2}$ Faculty Econimics and Business, University of Brawijaya, Malang, Indonesia
}

\begin{abstract}
This empirical research aimed to determine the organizational learning influence extent on the organizational core competencies and diversification strategy in improving the private university organizations performance in the East Nusa Tenggara province. This study was conducted in stages in order to determine the partial effect of organizational learning on the organization's core competencies, diversification strategies and organizational performance. The aforementioned aspect contributes to further studies in the strategy management. It concerns the effect of organizational learning on core competencies, diversification strategies and organizational performance, especially in organizing private universities. Previous research was reviewed to aid variables and hypothesis development. The variables used in the research are organizational learning, organizational core competencies, diversification strategies and work performance. The following stages were conducted through the course of the research: browsing articles, separating articles, extracting data, synthesizing data, reporting data. Data analysis method used path analysis. The approach used is quantitative positivists. The populations in this study were all private universities in the scope of Region VIII LLDIKTI Bali and Nusa Tenggara, focusing in East Nusa Tenggara. The sample were university and college in East Nusa Tenggara province: 40 PTS (High Education Institutions) consisting of 12 universities and 28 college. This study focused on the phenomenon occurred in NTT province higher education. The higher education organization management has not been well standardized. It exhibited low quality organizational competency, educational qualifications, lecturer competencies, facilities and infrastructure. Offered study programs are not in accordance with the regional condition. The graduate's competence does not suit the regional need. The local governments do not focus its effort in higher education. Regardless of this obstacle, the community keeps sending their children to higher education institutions. This is indicated by increased number of universities in NTT and high-interest rate in entering higher education. This condition encourages researchers to determine the phenomenon's crucial aspects. This research aim to illustrate how organizational learning, core organization competencies and diversification strategies need to be developed in improving private university institutions performance in NTT province.
\end{abstract}

Key words: Organizational learning, core organization competencies, diversification strategies, organizational performance, private universities organizations

\section{INTRODUCTION}

The 1945 constitution requires the government to seek and organize a national education system that enhances the faith and piety of God Almighty as well as a noble character in order to educate the nation. The philosophical explanation of the 1945 constitution is featured in article 31 of the 1945 constitution. The government must create a national education system. The national education system is expected to be able to guarantee equitable educational opportunities, improve quality, relevance and efficiency of education management to face challenges in accordance with local, national and global changes. Recognizing these obligations, the government issues legislation that regulates the obligations stated above. The government issues law. The 20 year 2003 concerning a national education system and its derivative products in the form of government regulation 17 year 2010. Education is defined as a conscious and planned effort to create a learning atmosphere and process. It is conducted to ensure students actively develop their potential, religious-spiritual power, self-control, personality, intelligence, noble character and skills required for the individual itself, society, nation and country.

The implementation of higher education level as indicated by the law concerning the national education system is carried out by the government through tertiary 
education. The division of higher education consists of: state universities (PTN), State official universities (PTK), religion based university (PTA) and tertiary institutions managed by the private sector through private universities (PTS). Changes in the political climate and increasingly unimpeded permits in conducting national education increases competition in education services. Tertiary educational institutions in Indonesia, both state and private, used to compete with domestic universities. However, current competitor involves various higher education institutions at regional and international levels. The national education industry must face various challenges. The higher education challenge is to prepare high-quality graduates. These graduates must possess academic skills (hard skills) supported by personality integrity and the socializing capability in the workforce (soft skills). The need to improve the quality of human resources through soft skills development is conducted through improving personal abilities (leadership, honesty, responsibility) responsibility, integrity and vision in the future), teamwork cooperation and work motivation. It requires universities to be able to display a positive image as a high-quality institution that cares about the social condition and is adaptive to various changes, developments and community demands.

The organizational learning in private universities can ideally make higher education institution as a home of excellence. Higher education is not merely a training station in the education process. Organizational learning in private universities increases the individuals work capacity to achieve the organization's vision, mission, goals and objectives. The ideal benefits gained by organizational learning in private universities are: the organization's ability to maintain innovation in order to remain competitive, remain steadfast to external pressure, possessing deeper knowledge in understanding client needs, improve output quality at all levels, increase the rate of change in all organizations and reduce employee turnover rates. According to Elfindri as quoted from Kompas ideal organizational learning in PTS is illustrated by the ability of PTS to adjust to various interests such as student's future interests in the form of external efficiency improvements. These are determined based on alumni short entry time into the labor market adjusted to the external conditions of the labor market and regional economy. The changing dimensions of labor market requirements indicate the need to adjust the curriculum, learning methods and students learning outcomes. PTS must immediately improve scientific orientations in order to produce high-quality graduates possessing skills and fast decision-making capability.

The ideal organization competence is illustrated by competency dimensions improvement. Lecturers must possess proper knowledge, attitude, values and skills. The lecturer competency dimension may encourage the improvement of lecturer competencies in terms of academic, professional, social and personality abilities. Furthermore, Teddy Chandra as quoted by Tribun Pekanbaru stated that professional lecturers should present in college lecture process. Professional lecturers produce high quality students. Professional lecturers must possess qualified competencies and qualifications. This indicates that the lecturers must possess above average skill in the related field. To achieve this capability, the lecturer must implement the tri dharma of higher education. Furthermore, according to Budi Hermana, a Gunadarma University lecturer as quoted by Media Indonesia, the ideal competency provision given PTS graduate students must be in line with study program and competencies. The combination of competency provisions and PTS facilities may produce competent PTS graduates.

The ideal conditions on diversification strategies are applied in higher education. According to Elvi Rosalin in developing competitive advantages of higher education, diversification in higher education should ideally provide opportunities and developments. It must be followed by quality and competitive advantage development. Fielden (2008) illustrates 4 dimensions of PT (university) performance: students, research, staff/ HR and finance/efficiency. These indicators can be used at the national level as well as at the PT institutional level. The ideal performance measurement dimension based on BAN PT featured additional measurement relevant to measure PT performance. This measurement dimension is service to students/academics. Ghignoni and Verashchagina (2014) added that PT's ideal performance is determined through the suitability of graduates compared to labor market needs. The work field a graduate can enter depends on the mastered qualifications and skills (Koda and Yuki, 2013).

The general phenomenon was determined through the data taken from BAN PT. In May, 2014, out of a total of 4.440 PTs, 576 PTs were under supervision and 103 PTs were closed. Out of the 163 accredited PTs, 21 PT have accredited A, 68 PT received B accreditation and 74 PT were accredited C. Until December, 2014, out of 22.306 study programs, 546 study programs had to be closed because they were not registered and only $16.98 \%$ were accredited. Regarding the quality of lecturers, out of 192.917 lecturers: $20.18 \%$ did not possess a master's degree, $38.28 \%$ did not possess academic positions and $2.38 \%$ posses's academic position as a professor. Out of all the existing lecturers, only 43.24\% were certified. Internal conflict between stakeholders, low quality of lecturers, the ratio of lecturers and students, illegal study program and the issuance of fake diplomas are existing PT issues. 
A similar phenomenon is faced by private universities in the East Nusa Tenggara province. As part of the region VIII LLDIKTI coordinator in Bali and Nusa Tenggara, the private universities (abbreviated as PTS) experience various obstacles. The constraints on the PTS development began with the organizer's low qualification. The accreditation level indicated by the higher education national accreditation agency (BAN-PT) cannot be fulfilled by PTS management. According to data from 52 PTS in the NTT region, less than a third of these PTS have been accredited, especially, regarding superior accreditation status. The next obstacle is the education supportive facilities and infrastructure. The absence of laboratories, libraries and other supporting facilities such as the internet and Wi-Fi. A number of universities in NTT do not possess university infrastructure and rent from other parties. There is lack of lecturer's competence and unideal ratio between the number of lecturers and student. Available study programs do not answer the needs of the community real conditions. For example, there are no PTS in the NTT province opens fisheries and tourism study programs.

It is necessary to have several other arguments on the importance of further research regarding the effects of organizational learning, organizational core competencies and diversification strategies on organizational performance in the context of higher education organizations.

Previous studies on the impact of organizational learning, organizational core competencies, diversification strategies and organizational performance in the field of strategic management paid more attention to general organizational organizations than higher education organizations (De Geus, 1988; Khandekar and Sharma, 2006). Regarding the diversification strategies affecting the performance achievement, the context of the study and research focuses on organizational organizations as presented by Hitt et al. (1998), Bettis and Mahajan (1985) and Coulter (2002). The findings of this study cannot be generalized due to differences in resources and organizational capabilities, leading to differences in behavior, competitive action and threat and business opportunities response speed. This research focused on higher education organizations, in this case, private universities. This research could not be compared due to differences in the organization size and the service approach.

Kumar (2005) "Assessing the Learning Culture and Performance of Educational Institutions" examines the effect of three levels of learning. These are organizational level, team and individual learning on financial performance and knowledge at private universities in Malaysia. In this study, Kumar (2005) focused on organizational learning at various levels which had an effect on Malaysia private universities performance as the object of research. This encourages the writer to determine how organizational learning using PTS approaches in Indonesia and further examines the organization's core competency model and diversification strategy in influencing organizational learning and performance.

Research and studies conducted in Indonesian universities as an object of research. Allen and Davis, 1991 were quoted with the title "Analysis of Differences in Service Quality in Higher Education Institutions in Surabaya" found both state universities (PTN) and private universities (PTS) compete in providing educational services to students and producing high or adequate quality graduates. In order to do so, the universities constantly improve themselves in order to maintain services quality and increase core competencies. This study did not specifically, examine how the influence of organizational learning on competence and diversification strategies to improve performance. In the study mentioned above, state universities and private universities were not separated.

Schein in Greaves and Sorenson cited by Syamsulhadi and Siswandari, "Concerning Future Universities" concludes that there are five criteria for an organization (including higher education) for it to be considered good and possess high-quality competencies. Regardless, it did not specifically focus on how the influences of organizational learning, organizational core competencies and diversification strategies have an effect on improving college performance.

Said's research "Strategic Factors Affecting the Quality of Service and Performance of PTN and PTS in Indonesia" stated that the strategic factors used are organizational learning, market analysis capabilities, technology leadership, employee empowerment and job satisfaction. The results of this study indicate that strategic factors have a significant direct effect on organization performance, organizational learning, market analysis skills and service quality. Other strategic factors such as technology leadership, employee empowerment and job satisfaction have no effect on performance. This research describes organizational learning that influences performance. Strategy factors such as core competency variables and diversification strategies were not considered by researchers. This encourages the study of the effects of organizational learning, core competencies and diversification strategies on private universities performance. It is conducted to determine the extent of the variables affect the higher education organizations performance and achievement.

Sukirno's research, "The Effect of Organizational Learning Opportunities and Teaching Quality on the Relationship between Lecturer Participation in Decision Making and Student Learning Outcomes in Higher Education Institution in Yogyakarta Special Region”, 
examine the relationship between lecturer participation in decision making on students learning outcomes using opportunities for organizational learning and teaching quality as intermediate variables. The study discussed organizational learning which led to improved performance. Regardless, there are no core competency variables such as knowledge competencies and diversification strategies to determine performance achievements.

Purnama (2002)'s research, “Analysis of the constraints of the potential application of Total Quality Services in Higher Education". Based on the measurement dimensions of Prieto and Revilla (2006) private university, organizational performance is depicted with financial performance in the form of smooth cash flow (in this case the tuition payment and all financial deposits do not experience delays and handling), sales growth (in this case the number of students assumed to increase annually) and non-financial performance consisting of the level of competition in maintaining customers by improving the higher education services quality. It is divided into three dimensions: improving services to students, increasing lecturer knowledge and university physical improvement and student GPA level. This motivates researchers to examine how the influence of organizational learning, core competencies and diversification strategies affect private universities performance.

Based on the above arguments, this research combined organizational learning models, organizational core competencies and diversification strategies possessing partial and simultaneous influence on organizational performance in private universities (PTS) in the strategic management studies. Mmost research in strategic management focuses its studies on public organizations such as research conducted by De Geus (1988), Khandekar and Sharma (2006), Hitt et al. (1998), Bettis and Mahajan (1985), Coulter (2002) and Wang and Lo (2003).

The focus of this research is private universities organization as an object of research. The studies conducted in the context of higher education organizations do not limit the discussion only to private universities. Some studies combine between private universities and state universities.

As a result, in terms of differences in resources, there are significant differences regarding private universities and state universities. Therefore, there is a need for studies and research to be conducted focusing on private universities.

Furthermore, there has been no research on the organization of private universities in the region VIII LLDIKTI of Nusa Tenggara and Bali, especially in the special region of East Nusa Tenggara. Various researches which have been described above are supported by contextual phenomena and research gaps and research renewal. Therefore, this research is carried out with the title "the influence of organizational learning, core organization competencies and diversification strategies on organizational performance in private universities”. The formulation of this research problem is described as follows:

- $\quad$ Does PTS organizational learning have a significant influence on PTS core competencies?

- $\quad$ Does PTS organizational learning have a significant influence on PTS performance?

- Does the PTS organization's core competency have a significant influence on PTS diversification strategies?

- Does the core competence of PTS organizations significantly influence PTS performance?

- Does the PTS diversification strategy have a significant influence on PTS performance?

Literature review: Organizational learning is the process by which organizations use existing knowledge and build a variety of new knowledge to shape the development of core organizational competencies crucial in a changing environment (Kogut and Zander, 1992; Henderson and Cockburn, 1994). According to Marquardt (1996), organizational learning can be built through the thought process, mental models, personal skills, teamwork, shared vision and dialogue. PTS continues to face pressure to make changes. Wang and Lo (2003), Murray and Donegan (2003) and Chaston et al. (1999) stated that organizational learning has a positive influence in developing organizational competencies.

The basis of the study on core competencies influence on performance in organizations was built by several studies such as those conducted by Pace et al. Competitive performance: a resource-based view approach in the software sector. Based on the Resource-Based View (RBV) approach, performance differences between organizations is due to differing specific resources and accumulated competencies. This study examined the relationship between competitive performance and strategic resources owned. Based on Durand (1999), research methodology the relative contributions of imitable, non-transferable and non-substitutable resources to profitability and market performance, the results of the relationship between the level of influence of productive assets and organizational performance are obtained. The previous research and studies explain the influence of competency on performance. Durand (1999), Wernerfelt (1984), O’Regan and Ghobadian (2004), Wang and Lo (2003), King and Zeithamal (2001), Fernandes et al. (2005), stated that organizational competence has an influence on organizational performance. 
Competency is defined as: “.... the ability and knowledge that form the basis of everyday problem-solving...” (Henderson and Cockburn, 1994). Leonard-Barton (1992) emphasizes the importance of knowledge and considers competence as a complex knowledge system that includes employee skills and learning, technology, managerial and organizational value systems. By optimizing the competencies, a sustained competitive advantage would emerge. The core competencies possessed will be a source of competitive advantage when universities possess valuable, scarce and difficult to replicate or replace competencies (Barney, 1991).

According to Bettis and Mahajan (1985), business diversification is the diversity of business types both related (related business) and non-related (unrelated business). The diversification strategy carried out by PTS is conducted by increasing the number of study programs. The addition of study programs endavor to meet the increasingly diverse user needs and ever-increasing demands. The diversification strategy strengthens the competitive position of PTS in the education industry. Previous studies explained the influence of competency on diversification strategies. Chatterjee and Wernerfelt (1991), Markides and Williamson (1996), Silverman (1999), Lemelin (1982), Stewart et al. (1984) and Barney (1991), stated that organizational competence has influence and is closely related to organizational diversification strategies.

The core competencies will determine and maintain the competitive position of the organization in its industry. PTS core competency is discussed as the ability of PTS to provide and pay attention to human resources and argues that resources produce unique, intangible and difficult to imitate or replace competencies (Oliver, 1997). The intended human resources are PTS lecturers. The previous studies and research explained the influence of organizational learning on organizational performance. Lopez et al. (2005), Khandekar and Sharma (2006), Murray (2003), Bontis et al. (2002), Kumar (2005) and Prieto and Revilla (2006) stated that organizational learning has an influence in creating and developing the performance of higher education organizations.

These studies explained the influence of diversification strategies on performance. Rumelt (1982), Stimpert and Duhaime (1997), Bettis (1981), Christensen and Montgomery (1981), Ammit and Livnat (1988), Michel and Shaked (1984), Lloyd and Jahera(1994) and De (1992), stated that those organizational diversification strategies have an influence on organizational performance.

Hypothesis: The hypothesis is a proposition of a temporary answer to the problem under study. It needs to be tested quantitatively. The hypothesis in this study is described as follows:
- $\mathrm{H}_{1}$ : there is a significant influence of organizational learning on the PTS core competencies

- $\mathrm{H}_{2}$ : there is a significant influence of organizational learning on PTS organizational performance

- $\mathrm{H}_{3}$ : there is a significant influence of core competencies on PTS diversification strategies

- $\mathrm{H}_{4}$ : there is a significant influence of core competencies on PTS organizational performance

- $\mathrm{H}_{5}$ : there is a significant influence of PTS diversification strategy on PTS organizational performance

\section{MATERIALS AND METHODS}

This study aims to examine the influence of organizational learning abilities, core competencies and diversification strategies on private universities performance in East Nusa Tenggara province. This research used explanatory research.

The study was conducted at all private universities in the scope of region VIII LLDIKTI Bali and Nusa Tenggara, especially in the East Nusa Tenggara province consisting of universities, colleges, polytechnics and academies. The population is the total number of elements studied (Cooper and Schindler, 2006). This study used analysis at the organizational level. The population is all private universities (PTS) in LLDIKTI in Bali and Nusa Tenggara, focused East Nusa Tenggara (NTT) province. In this case, represented by the leadership elements of private universities. The population in this study was 52 private universities in East Nusa Tenggara. It consists of 12 universities, 28 colleges, 4 polytechnics and 8 academies. Samples are part of the population data considered to represent the population (Cooper and Schindler, 2006). The sample in this study was universities and colleges in region VIII LLDIKTI Bali and Nusa Tenggara, focusing on East Nusa Tenggara (NTT). The samples were 40 private universities consisting of universities and colleges.

The sample selection criteria were based on the size of the organization, referring to the 2014 education and culture Regulation No. 139 concerning the statute of organizations in higher education. This regulation implies that higher education organizations are divided based on the university, colleges, academics and vocational programs. Based on these rules, the academic, polytechnic organization and vocational programs cannot be included in the study sample as they are considered equivalent to the faculty at a university or college level. The unit of analysis in this study is private universities (PTS). The respondents or informants were the leadership elements, namely (Chancellor, Deputy Chancellor I, II and III or Chairperson, Deputy Chairperson I, II and III), other leadership elements (Dean, Deputy Dean and Chair of Study Program) and heads of BAK. Path analysis was 
utilized in this study to assess the hypothesis in the SPSS program. According to Solimun path analysis are described as follows:

Arrange causal models: Based on variable/construct relationships, a model can be made in the form of a path diagram. The available model is expressed in the form of structural equations. The system of equations is formed as follows:

- $\quad \mathrm{PO}=\beta+\beta 1 \mathrm{KIO}+\mathrm{e} 3$

- $\quad \mathrm{PO}=\beta+\beta 1 \mathrm{KO}+\mathrm{e} 3$

- $\mathrm{KIO}=\beta+\beta 1 \mathrm{SD}+\mathrm{e} 3$

- $\mathrm{KIO}=\beta+\beta 1 \mathrm{KO}+\mathrm{e} 3$

- $\mathrm{SD}=\beta+\beta 1 \mathrm{KO}+\mathrm{e} 3$

Which is then standardized as follows:

- $\quad \mathrm{ZPO}=\mathrm{ZP}_{1}+\mathrm{Z} 11 \mathrm{KIO}+\mathrm{e} 3$

- $\mathrm{ZPO}=\mathrm{ZP}_{2}+\beta 1 \mathrm{KO}+\mathrm{e} 3$

- $\mathrm{ZKIO}=\mathrm{ZP}_{3}+\beta 1 S D+\mathrm{e} 3$

- $\quad \mathrm{ZKIO}=\mathrm{ZP}_{4}+\beta 1 \mathrm{KO}+\mathrm{e} 3$

- $\mathrm{ZSD}=\mathrm{ZP}_{5}+ß 1 \mathrm{KO}+\mathrm{e} 3$

Description:

PO : Organizational learning

KIO : Organization Core Competence

SD : Diversification Strategy

KO : Organizational Performance

Based on the models of influence, the trajectory models were arranged as follows. This path model is called path analysis which error is determined as follows:

$$
\mathrm{P}_{\mathrm{ei}}=\sqrt{1-\mathrm{R}_{1}^{2}}
$$

Determining the direct influence with the path approach: To explain the relationship in the same direction, the standardize regression variable is partially used in each equation.

Determining indirect influences: The indirect effect of the independent and dependent variable was not conducted in this study as there were no indirect influences.

Examination of model validity: Model validity in path analysis used a total coefficient of determinations and trimming theory. Total coefficient of determination. The total data diversity that can be explained by the model is measured by:

$$
\mathrm{Rm}^{2}=1-\mathrm{Pe}_{1}^{2}+\mathrm{Pe}_{2}^{2}+\mathrm{Pe}_{3}^{2}+\mathrm{Pe}_{4}^{4} \mathrm{Pe}_{5}^{5}
$$

Theory trimming, the validity test of the path coefficient on each path for direct influence was similar to the regression using the p-value of the t-test, namely the variable regression coefficient assessment is partially standardized.

\section{Hypothesis assessment using multiple linear regression requires model assessment using \\ Determinant coefficient (R2): The coefficient of determination was used to measure the model ability to explaining variations in the dependent variable. The statistical formula for the coefficient of determination is as follows, $\mathrm{KD}=\left(\mathrm{r}^{2}\right) \times 100 \%$.}

Significant t-test: The $\mathrm{t}$ statistic test exhibits the influence of one explanatory variable in explaining the dependent variable. The t-test was done by comparing tcount with t-table in the $t$ distribution table with an error rate of $5 \%$ to determine whether the hypothesis is rejected or accepted.

Significant F-test: Significant F-test was done using the value of F-count and F-table in the F-table distribution with an error rate of $5 \%$ to determine whether the proposed hypothesis is received or rejected.

\section{RESULTS AND DISCUSSION}

Hypothesis assessment used regression analysis to determine the magnitude of each construct of each variable. The magnitude of the relationship is exhibited in the standard coefficient (beta) of each variable and assessed in a t-test. The regression analysis using SPSS Version 21 Software was conducted on the 5 hypothesis. Furthermore, the results of hypothesis assessment are exhibited in Table 1.

The regression test results obtained regression coefficient $(\beta)$ of 0.339 with a significant level of probability values $<0.05$. The results of the t-test exhibited t count 5.667>t table 1.96. Assessment result concluded that hypothesis 1 is supported.

The regression test results obtained regression coefficient $(\beta)$ of 0.468 with a significant level of probability values $<0.05$. The results of the t-test exhibit t count 8.340>t table 1.96. Assessment result concluded that hypothesis 2 is supported.

The regression test results obtained the regression coefficient value $(\beta)$ of 0.261 with a significant level of probability values $<0.05$. The results of the t-test exhibit t count 4.257>t table 1.96. Assessment result concluded hypothesis 3 is supported.

The regression test results obtained regression coefficient $(\beta)$ of 0.420 with a significant level of probability values $<0.05$. The results of the t-test exhibited t count is 7.299>t table 1.96. Assessment result concluded hypothesis 4 is supported. 
Table 1: Summary of the structural equation research model

\begin{tabular}{llllllll} 
& & & \multicolumn{3}{c}{ Level of direct relations } & \\
Hypothesis & Independent variables & Dependent variables & B & T & SE & p sig & Description \\
\hline 1 & Organizational learning & Organizational core competencies & 0.339 & 5.667 & 0.077 & 0.000 & Supported \\
2 & Organizational learning & Organizational performance & 0.468 & 8.340 & 0.052 & 0.000 & Supported \\
3 & Organizational core competencies & Diversification strategy & 0.261 & 4.257 & 0.048 & 0.000 & Supported \\
4 & Organizational core competencies & Organizational performance & 0.420 & 7.299 & 0.080 & 0.000 & Supported \\
5 & Diversification strategy & Organizational performance & 0.598 & 11.75 & 0.047 & 0.000 & Supported \\
\hline
\end{tabular}

Table 2: Path analysis model

\begin{tabular}{llll}
\hline Hypothesis & Independent variables & Dependent variables & Beta coefficient value $(\beta)$ \\
\hline 1 & Organizational learning & Organizational core competencies & 0.339 \\
2 & Organizational learning & Organizational performance & 0.468 \\
3 & Organizational core competencies & Diversification strategy & 0.261 \\
4 & Organizational core competencies & Organizational performance & 0.420 \\
5 & Diversification strategy & Organizational performance & 0.598 \\
\hline
\end{tabular}

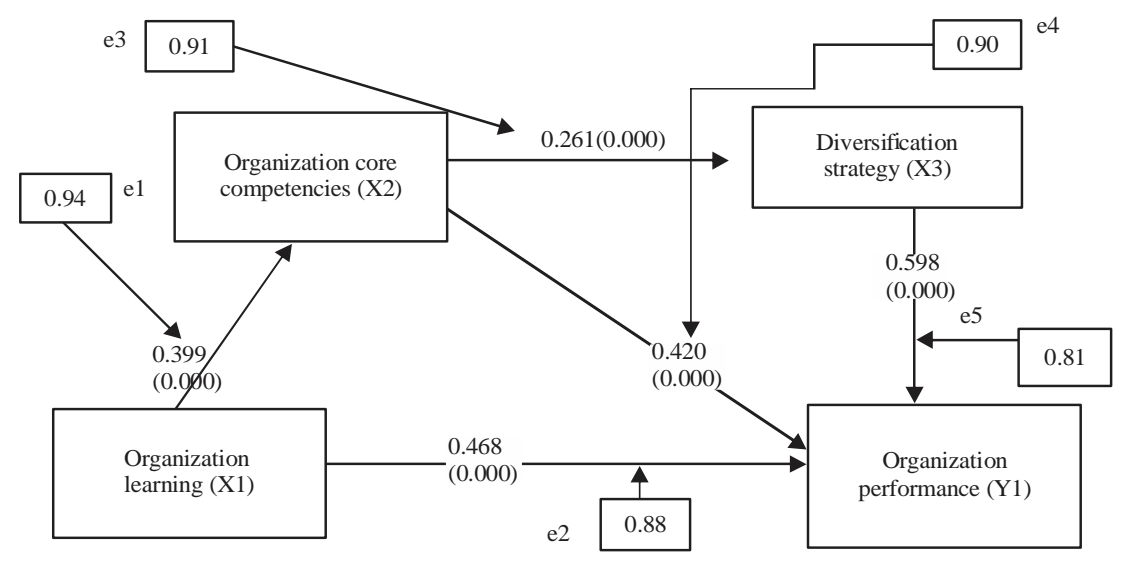

Fig. 1: Image of the PATH analysis model of the study

The regression test results obtained regression coefficient $(\beta)$ of 0.598 with a significant level of probability values $<0.05$. The results of the t-test exhibited t count 11.752>t table 1.96. Assessment result concluded hypothesis 5 is supported.

All research results from each hypothesis in the study are all supported. It can be concluded that organizational learning, organizational core competencies and diversification strategies have a positive and significant influence on improving private universities performance in East Nusa Tenggara. The results of the full path analysis are exhibited in Table 2 explanation.

There is a direct relationship between organizational learning and organizational core competencies with a beta value of 0.339 , between organizational learning and organizational performance with a beta value of 0.468 , between organizational core competencies and diversification strategies with a beta value of 0.261 , between core competencies and performance organization with beta values with a value of 0.420 and a diversification strategy with organizational performance with a beta value of 0.598 .

The results of this path analysis are based on the regression output to exhibit the direct relationship or indirect relationship of this study. Based on the models of influence, a path model was arranged. Its error was determined as follows:

$$
\begin{aligned}
& \mathrm{P}_{\mathrm{ei}}=\sqrt{1-\mathrm{R}_{1}^{2}} \\
& \mathrm{P}_{\mathrm{ei}}=\sqrt{1-0.115}=0.94 \\
& \mathrm{P}_{\mathrm{e} 2}=\sqrt{1-0.219}=0.88 \\
& \mathrm{P}_{\mathrm{e} 3}=\sqrt{1-0.168}=0.91 \\
& \mathrm{P}_{\mathrm{e} 4}=\sqrt{1-0.177}=0.90 \\
& \mathrm{P}_{\mathrm{e} 5}=\sqrt{1-0.358}=0.81
\end{aligned}
$$

it is expressed in more detail on Fig. 1 path analysis. The path analysis model examination used the total determinant coefficient value. Model validity assessment used the total coefficient of determination value to determine the total data diversity using the following formula:

$$
\begin{aligned}
& \mathrm{R}^{2} \mathrm{~m}=1-\mathrm{Pe}_{1}^{2}+\mathrm{Pe}_{2}^{2}+\mathrm{Pe}_{3}^{2}+\mathrm{Pe}_{4}^{4}+\mathrm{Pe}_{5}^{5} \\
& \mathrm{R}^{2} \mathrm{~m}=1-(0.077)(0.052)(0.048)(0.080)(0.047) \\
& \mathrm{R}^{2} \mathrm{~m}=1-0.0019546 \\
& \mathrm{R}^{2} \mathrm{~m}=0.980454
\end{aligned}
$$


The total coefficient of determination is 0.980454 . It indicates that the information contained in the data or the variables contribution explained by the model is $98.04 \%$. The rest is influenced by other variables or errors. The total coefficient of determination value exhibits that the model is very feasible and can be further interpreted. Path analysis results exhibited that organizational learning, organization core competency and diversification strategies have an important role in improving work performance at private universities in the East Nusa Tenggara province.

The influence of organizational learning on the of private universities organizations core competencies: The thought process indicator suggests the private universities in NTT province encourage lecturer's improvement by providing study opportunities. However, the PTS resources and capabilities level differs. Some PTS possess adequate resource to improve thought process while the others do not possess adequate resources.

The empirical results support Wang and Lo (2003) on customer-focused performance and dynamic models for competence building and leveraging: a resource-based view. Wang and Lo (2003) found that organizational learning has a positive effect on the organization's core competencies. The mental model indicator suggests PTS organizations motivate lecturer's improvements through comparative studies and improve teaching methods. However, not every PTS organizations in NTT allocate funds and provide opportunities for lecturer's improvement. It is indicated by mental models development such as weak literacy culture, strong paternalistic culture, easily satisfied with obtained achievement, seniority culture in an organization and reluctance to exit comfort zone. However, mental model indicators are able to encourage the development of PTS organizational competencies. The empirical results of mental model indicators from this study are supported by Murray and Donegan (2003) stating that organizational learning connected through a number of levels is a factor that determines organizational competency development.

The influence of organizational learning on private university organizational performance: Organizational learning indicators outline the importance of teamwork in improving PTS organizational performance. Teamwork indicators encourage the ability of coordinative and innovative work as well as close collaboration between lecturers and employees. Almost every PTS in NTT strives to improve work performance. They facilitate training for teaching material writing, material depth and methodology and literacy improvement. They also encourage research and service improvement. There are independent research and service funds available at PTS.
Regardless of the small number of funds available, this exhibits the PTS organizations willingness in improving performance. Most PTS in NTT collaborate with state and private universities in Java as well as foreign universities. This is in line with Sukirno's research (1999) states that teaching quality influences student learning outcomes. The better lecturer mastery over teaching method approaches, media and principles, the easier it will be for students to understand the material. This would produce superior performance such as graduates with a high GPA, increasing number of students, high ability to retain students, better reputation and high financial performance. Friedman et al. stated that organizational learning will not be long-lasting if members of the organization have no interest in learning. Organizational learning indicators in the form of the ability to share a vision are represented by the ability to socialize the organization's vision to all members of the organization and the individual goals suitability level with the organization. The findings on these indicators indicate that PTS organizations in NTT endeavored to improve management governance. The high demands on higher education governance management from the Ministry of Education and Culture Encourage Improvement. Despite no existing A accredited PTS institution in NTT, there have been several universities, colleges and study program possessing $\mathrm{B}$ accreditation. The accreditation value increase is expected to improve PTS work performance in NTT. The improved work performance was demonstrated by the improvement of services to students, research, community service, financial efficiency, staff performance and cooperation between universities and work field. Furthermore, the empirical results of this study indicate that there must be cooperation between universities and the work field, especially in professional education. This is consistent with Brew and Boud (1996) stating that education adapted to workforce needs is crucial for students.

The influence of core competencies on private university diversification strategy: Indicators of competency values are represented by two factors: competency produces competitive advantage and lecturer's competency supports PTS competitive ability. Research result exhibited that NTT PTS does not offer study programs reflecting the superiority and uniqueness of competency values. Several study programs offer unique competencies and are in accordance with regional needs. For example, fisheries study programs in all NTT provinces are available in Nusa Nipa University in Sikka district, Flores island. The Dryland Agriculture study program is available at Flores University, Flores Island. These study programs have not been fully developed as a future scientific reference. The empirical results of this study are in accordance with Porter (1998) stating that an 
organization can achieve a competitive advantage if it has expertise or competencies to be channeled into new markets. Resources and competencies have long been believed to be one of the key factors in explaining diversification (Penrose, 1995). Rumelt (1974) discusses the need for "core expertise" capable to be used in related markets. PTS diversification strategy in adding study program is a step to strengthen its competitive position. It is conducted to face various changes in the external environment. This is in accordance with Levine research stating that students are increasingly heterogeneous. Their educational needs are also increasingly diverse and their desires cannot be managed properly. Levine referred to this phenomenon as a complete "supermarket model of education”.

The influence of organization core competencies on private university organizational performance: The indicator of the organizational competencies scarcity level represented by competencies is only possessed by PTS. The level of difficulty in finding or obtaining substitutes for PTS lecturer competencies and uniqueness. The empirical results indicate that a number of PTS offer the lecturer's education uniqueness level in proposing and opening new study programs. NTT PTS management realized that the study program must be based on the lecturers and organizations competence in order to compete. Over the past 5 years, PTS endeavored to open animal husbandry, fisheries, dry land agriculture, tourism, sports and other study programs. These study programs were based on existing human resource competency and developments.

Lecturer competency is one of the factors that drive a person to choose to study at a university. A high competency creates a good image in the community. Thus, PTS possessing high expertise lecturers is capable to attract prospective students. In other words, PTS will be able to retain students. The empirical results of this study are in accordance with Godfrey and Hill (1995). Difficult to replicate competencies are the core (axis) of resource-based view theory and the central understanding of sustainable competitive advantage (Spender and Grant, 1996). Furthermore, Pace et al. (2005) found that hard to imitate competencies had a positive relationship with performance. Competencies may be protected from imitation in various ways. Competence derived from historical factors (Barney, 1991) such as strategic location, copyright ownership (Rumelt, 1982) will protect these valuable resources from competitor's imitation attempt. The results of this study strengthen the research conducted by Absah. Assessing the influence of organizational learning abilities on competency, diversification level and organizational performance at private universities in North Sumatra and Aceh.
The influence of organizations diversification strategies on private university organizational performance: The fifth hypothesis in this study empirically represented by interrelationship indicator level between competency development, study programs, facilities and infrastructure usage level. NTT PTS management added new study programs based on the indicators above. For example, after the campus opened a civil engineering study program, it attempted to open the architectural engineering study program. This occurred in Flores University, Ende, Flores island; Widya Mandiri University in Kupang, Timor island. Universities possessing agricultural study program opened agribusiness and agro-technology programs. NTT PTS management strives to increase the number of study programs regardless of correlation. PTS increased the number of study program as an attempt to increase competitiveness. The empirical results of this study are in accordance with Rumelt (1982). A related diversification strategy is limited to categorizing moderate to high diversification levels. Regardless, decision makers at PTS need to remember that continuously added diversification levels would reduce performance.

\section{CONCLUSION}

Based on the analysis of research results, the following conclusions were drawn: organizational learning can encourage the creation of core competencies and private universities performance. This is indicated by private universities encouraging core competencies creation and organizational performance achievement. It is conducted by providing assistance to lecturers to continue formal and non-formal education, providing opportunities for lecturers to increase knowledge on teaching/working method, develop thought processes and motivate continuous self-improvement. PTS organizations encourage performance achievement through achieving predetermined targets, knowledge and technology, coordinative and innovative work ability and creating close collaboration between lecturers and employees.

Good core competencies will be able to create a diversified strategy and improve private universities performance. As core competencies are a source of competitive advantage, private universities and lecturers increase competitive ability. In turn, it create diversification strategies achievement. The core competencies is capable to boost private universities performance which are caused by several factors. These factors are, among others, the PTS unique competencies and PTS lecturer's sunique competencies. The competitors would experience difficulty and require a huge sum of funds in order to replicate the competencies.

Diversification strategies encourage private universities performance achievement. In principle, the 
diversification strategy encourages study programs additions. There is a correlation between the existing study program and infrastructure shared usage level.

Based on the conclusions of the research results and experience in the field, the following conclusions were drawn: private universities management must be able to encourage organizational learning to ensure it achieves core competencies and ideal organizational performance. There needs to be a commitment from the private universities management in East Nusa Tenggara province. It is conducted to encourage increased competency and performance by providing opportunities and funding. Regardless, not every private university possess strong and continuous commitment to encourage lecturer's self-improvement, provide research funding, attend national and international seminars, nor providing special funds to publish lecturer's research in national and international journals. It is necessary to encourage lecturer's personal development on knowledge and technology, coordinative and innovative manner work capability and create close collaboration between lecturers and employees.

The organization core competencies may encourage diversification and employment strategies achievements. The core competencies and superior performance improve private universities competitive advantage. Increased lecturers ability support private universities competitive capability. The limited competence of lecturers, facilities and infrastructure is a common occurrence in Indonesian universities, more so in NTT PTS. Regardless, this limitation should not discourage management performance. The management must always innovate to achieve superior PTS performance.

Diversification strategies that can be used by PTS management to improve work performance is opening a study program capable to create new jobs opportunity adhering to regional needs such as animal husbandry and tourism. A wise choice of diversification strategies can improve the work performance of the private universities concerned. In this case private universities in NTT.

\section{REFERENCES}

Barney, J.B., 1991. Firm resources and sustained competitive advantage. J. Manage., 17: 99-120.

Bettis, R.A. and V. Mahajan, 1985. Risk/return performance of diversified firms. Manage. Sci., 31: 785-799.

Bettis, R.A., 1981. Performance differences in related and unrelated diversified firms. Srategic Manage. J., 2: 379-393.

Bontis, N., M.M. Crossan and J. Hulland, 2002. Managing an organizational learning system by aligning stocks and flows. J. Manage. Stud., 39: 437-469.
Brew, A. and D. Boud, 1996. Preparing for new academic roles: An holistic approach to development. Int. J. Acad. Dev., 1: 17-25.

Chaston, I., B. Badger and E. Sadler-Smith, 1999. Organisational learning: Research issues and application in SME sector firms. Int. J. Entrepreneur. Behav. Res., 5: 191-203.

Chatterjee, S. and B. Wernerfelt, 1991. The link between resources and type of diversification: Theory and evidence. Strategic Manage. J., 12: 33-48.

Cooper, D.R. and P.S. Schindler, 2006. Business Research Methods. 9th Edn., McGraw-Hill Education, New York, USA., ISBN:9780072979237, Pages: 744.

Coulter, M.K., 2002. Strategic Management in Action. 2nd Edn., Prentice Hall, Upper Saddle River, New Jersey, USA., ISBN-13: 978-0130400062, Pages: 396.

De Geus, A.P., 1988. Planning as learning. Harvard Bus. Rev., 66: 70-74.

Dierickx, I. and K. Cool, 1989. Asset stock accumulation and sustainability of competitive advantage. Manage. Sci., 35: 1504-1511.

Durand, R., 1999. The relative contributions of inimitable, non transferable and non substitutable resources to profitability and market performance. Master Thesis, Goizueta Business School, Emory University, Atlanta, Georgia.

Fernandes, B.H.R., J.F. Mills and M.T.L. Fleury, 2005. Resources that drive performance: An empirical investigation. Int. J. Productivity Perform. Manage., 54: 340-354.

Fielden, J., 2008. Global Trends in University Governance. World Bank, Washington, USA.,.

Ghignoni, E. and A. Verashchagina, 2014. Educational qualifications mismatch in Europe. Is it demand or supply driven?. J. Comp. Econ., 42: 670-692.

Godfrey, P.C. and C.W.L. Hill, 1995. The problem of unobservables in strategic management research. Strat. Manage. J., 16: 519-533.

Henderson, R. and I. Cockburn, 1994. Measuring competence? Exploring firm effects in pharmaceutical research. Strat. Manage. J., 15: 63-84.

Hitt, M.A., B.W. Keats and S.M. DeMarie, 1998. Navigating in the new competitive landscape: Building strategic flexibility and competitive advantage in the 21st century. Acad. Manage. Executive, 12: 22-42.

Khandekar, A. and A. Sharma, 2006. Organizational learning and performance: Understanding Indian scenario in present global context. Educ. Training, 48: 682-692.

King, A.W. and C.P. Zeithaml, 2001. Competencies and firm performance: Examining the causal ambiguity paradox. Strategic Manage. J., 22: 75-99. 
Koda, Y. and T. Yuki, 2013. The labor market outcomes of two forms of cross-border higher education degree programs between Malaysia and Japan. Int. J. Educ. Dev., 33: 367-379.

Kogut, B. and U. Zander, 1992. Knowledge of the firm, combinative capabilities and the replication of technology. Organiz. Sci., 3: 383-397.

Kumar, N., 2005. Assessing the learning culture and performance of educational institutions. Perform. Improv., 44: 27-32.

Lemelin, A., 1982. Relatedness in the patterns of interindustry diversification. Rev. Econ. Stat., 64: 646-657.

Leonard-Barton, D., 1992. Core capabilities and core rigidities: A paradox in managing new product development. Strat. Manage. J., 13: 111-125.

Lopez, S.P., J.M.M. Peon and J.V.C. Ordas, 2005. Organizational learning as a determining factor in business performance. Learn. Organiz., 12: 227-245.

Markides, C.C. and P.J. Williamson, 1996. Corporate diversification and organizational structure: A resource-based view. Acad. Manage. J., 39: 340-367.

Marquardt, M., 1996. Building the Learning Organization: A Systems Approach to Quantum Improvement and Global Success. McGraw Hill, New York.

Murray, P. and K. Donegan, 2003. Empirical linkages between firm competencies and organisational learning. Learn. Organ., 10: 51-62.

O`Regan, N. and A. Ghobadian, 2004. The importance of capabilities for strategic direction and performance. Manage. Decis., 42: 292-312.
Oliver, C., 1997. Sustainable competitive advantage: Combining institutional and resource-based views. Strategic Manage. J., 18: 697-713.

Penrose, E., 1959. The Theory of the Growth of the Firm. 3rd Edn., Oxford University Press Inc, New York, USA.,.

Porter, M., 1998. Competitive Advantage: Creating and Sustaining Superior Performance. Free Press, New York, USA., Pages: 592.

Prieto, I.M. and E. Revilla, 2006. Learning capability and business performance: A non-financial and financial assessment. Learn. Organ., 13: 166-185.

Rumelt, R.P., 1974. Strategy, Structure and Economic Performance. Harvard University, Cambridge, Massachusetts, ISBN-13: 978-0875841090, Pages: 249.

Rumelt, R.P., 1982. Diversification strategy and profitability. Strategic Manage. J., 3: 359-369.

Silverman, B.S., 1999. Technological resources and the direction of corporate diversification: Toward an integration of the resource-based view and transaction cost economics. Manage. Sci., 45: 1109-1124.

Spender, J.C. and R.M. Grant, 1996. Knowledge and the firm: Overview. Strategic Manage. J., 17: 5-9.

Stewart, J.F., R.S. Harris and W.T. Carleton, 1984. The role of market structure in merger behavior. J. Ind. Econ., 32: 293-312.

Wang, Y. and H. Lo, 2003. Customer-focused performance and the dynamic model for competence building and leveraging: A resource-based view. J. Manage. Dev., 22: 483-526.

Wernerfelt, B., 1984. A resource-based view of the firm. Strategic Manage. J., 5: 171-180. 